FedUni ResearchOnline https://researchonline.federation.edu.au

This article is (c) Emerald Group Publishing and permission has been granted for this version to appear here. Emerald does not grant permission for this article to be further copied/distributed or hosted elsewhere without the express permission from Emerald Group Publishing Limited.

The final published version of this article can be found at:

https://doi.org/10.1108/QAOA-11-2017-0048 


\title{
To err is human: medication patient safety in aged care, a case study
}

\author{
Julia Gilbert and Jeong-ah Kim
}

\begin{abstract}
Purpose - The purpose of this paper is to explore an identified medication error using a root cause analysis and a clinical case study.

Design/methodology/approach - In this paper the authors explore a medication error through the completion of a root cause analysis and case study in an aged care facility.

Findings - Research indicates that medication errors are highly prevalent in aged care and 40 per cent of nursing home patients are regularly receiving at least one potentially inappropriate medicine (Hamilton, 2009; Raban et al., 2014; Shehab et al., 2016). Insufficient patient information, delays in continuing medications, poor communication, the absence of an up-to-date medication chart and missed or significantly delayed doses are all linked to medication errors (Dwyer et al., 2014). Strategies to improve medication management across hospitalisation to medication administration include utilisation of a computerised medication prescription and management system, pharmacist review, direct communication of discharge medication documentation to community pharmacists and staff education and support (Dolanski et al., 2013).

Originality/value - Discussion of the factors impacting on medication errors within aged care facilities may explain why they are prevalent and serve as a basis for strategies to improve medication management and facilitate further research on this topic.
\end{abstract}

Keywords Case study, Medication management, Aged care, Root cause analysis, Medication error, Polypharmacy

Paper type Case study

\section{Introduction}

The ageing population may well become the next global health challenge as advances in medicine and medical procedures have increased the expected lifespan of many elderly people (Suzman et al., 2014). Whilst individuals may experience increased longevity, increased incidence of multiple co-morbidities may result in increased admission rates to aged care facilities as individuals struggle to live in the community alone (Britt et al., 2008). In conjunction with increased co-morbidities, individuals may experience polypharmacy, one of the leading causes of medication errors (Fialova and Onder, 2009). Unintended discrepancies between a patient's home medication regime, hospital discharge orders and inadequate communication between health care providers at transition from hospital to the community increase the likelihood of medication errors (Barker et al., 2002).

The aim of this paper is to discuss medication patient safety utilising a medication error case study and root cause analysis relating to an elderly man in an aged care facility.

\section{Background}

Medical errors kill between 210,000 and 440,000 people per year, more than from highway accidents, breast cancer or AIDS combined (Sammer et al., 2010). Statistics reveal that preventable medical errors in hospitals are responsible for 11 per cent of all deaths globally (Gautam, 2013).

Julia Gilbert is Lecturer at the Federation University, Victoria, Australia.

Jeong-ah Kim is based at the Federation University, Victoria, Australia.
Received 15 November 2017 Revised 4 May 2018 Accepted 4 May 2018 
A staggering 19 per cent of preventable deaths are due to incorrectly researched, prescribed and administered medications, with an economic cost of approximately $\$ 1$ tn globally over the past decade (Jamens, 2013). Although estimates of the size of the problem are scarce in developing and transitional countries, it is likely that millions of patients worldwide suffer disabilities, injuries or death every year due to medication errors (WHO, 2017). Medications are the most common therapeutic intervention used in aged care facilities with many residents taking ten or more different medicines for various health conditions, increasing their likelihood of experiencing a medication error (Department of Health and Ageing, 2012; Gurwitz et al., 2000).

A case study and root cause analysis will be used to explore factors involved in a medication error involving an elderly man transitioning from hospital to an aged care facility.

\section{Case study}

Peter Franks, an 86 year old man with type 2 diabetes Mellitus, osteoarthritis and hypertension has lived in Happy Valley Aged Care Facility for three years. Peter was admitted to the local hospital one week ago for community acquired pneumonia and returned to the facility yesterday.

During his hospitalisation, he experienced labile blood glucose levels, so his oral hypoglycaemics were ceased and he was commenced on Lantus insulin 20 units nocte. Peter's usual medications prior to admission to hospital included glipizide $10 \mathrm{mg}$ and metformin $1,000 \mathrm{mg}$ once a day. Peter was discharged to the aged care facility at $7.30 \mathrm{pm}$ on a Saturday due to the need for his hospital bed. The medical officer completing the discharge medication form inadvertently included Peter's usual oral hypoglycaemic medication in addition to the Lantuson the discharge medication chart.

On arrival at Happy Valley Aged Care Facility, Amy Miller, the Registered Nurse looking after Peter, read through his hospital discharge information and then filed it in his chart without ringing Peter's General Practitioner and notifying him of Peter's return to the facility and his current discharge medications. She did send the General Practitioner a fax informing him of Peter's return but the GP would not receive this until Monday. Amy had graduated from Smithfield University one month ago, and this was her first employment as a Registered Nurse.

She also did not identify that both Peter's usual oral hypoglycaemics and Lantus were ordered and so she administered the oral hypoglycaemics as charted. Later that afternoon, Peter was found to be cold, clammy and unresponsive by nursing staff. Peter's blood glucose level was found to be $2.1 \mathrm{mmol} / \mathrm{l}$ and Amy organised for Peter to be urgently transported to hospital by ambulance.

The Happy Valley Director of Nursing had a professional and ethical obligation to discuss the medication error with Amy, issue her with a warning and include a note regarding the error in Amy's employee file.

\section{Analysis process-how and why did this medication error occur?}

A root cause analysis was utilised to explore the factors relating to this medication error scenario. Factors identified included:

- the hospital and aged care facility environments where staff members experienced heightened stress levels and increased workloads;

- poor organisational culture where the aged care facility nurse was not supported by the organisation;

- clinicians work and life experience where junior staff members with limited work experience were given tasks beyond their capability; and

- poor communication across and within organisations commencing with the medication prescription process and culminating in the administration of the medication (Dolanski et al., 2013).

This analysis was conducted based on the discharge medication documentation, statements from medical, nursing and pharmacy staff and the aged care facilities medication error record. It was also used to provide an opportunity to identify improvement strategies which may reduce the incidence of medication errors by investigating and understanding all the elements in the medication administration process. 
When first exploring this medication error scenario, it was noted that Peter experienced a change in medication within the hospital with the cessation of his oral hypoglycaemics and commencement of Lantus. The information was clearly documented in Peter's inpatient medication chart. The discharging medical officer was a junior resident who had never seen Peter and did not fully know his medical history or progress during his hospitalisation. As a junior medical practitioner, he was allocated 14 medical patient discharge summaries including discharge medication forms to complete within two hours.

The discharge summary and medication forms needed to be handwritten as the hospital's computer service was not functioning for $16 \mathrm{~h}$. Electronic medication management systems are considered to be the gold standard for hospitals, reducing turnaround time for medication dispension by the use of closed loop order processing (Panosh et al., 2012). The time from prescription to first medication dose administration using an electronic medication management system has been identified as half the time of a paper based system, improving communication and decreasing the likelihood of errors (Leach, 2006).

The junior medical officer had not used the paper based medication discharge form before and was unfamiliar with what information he had to complete and he was reluctant to contact his supervisor and be considered incompetent. As noted, the usual medication management system in this hospital was an electronic system but because the system was unavailable, unfamiliar paper forms were used by the junior medical officer, increasing the risk of medication errors.

Whilst completing these patient discharge summaries, the junior medical officer was also first contact for any issues relating to the other $\mathbf{4 0}$ medical patients seen by all the medical teams in the hospital, and he received multiple pages and telephone calls to evaluate other patients during this time. Due to this high workload, unfamiliar paper based documentation and frequent interruptions, he was unable to concentrate fully on the discharge documentation process. As a result, he failed to fully check Peter's history, hospital medication chart and pre admission medications, increasing the risk of initiating a medication error for Peter (Elliott et al., 2012; Pierce and Fraser, 2009). The impact of frequent interruptions, multitasking and high workloads have been identified as adversely impacting on patient care, including medication errors, increasing the likelihood of a medication error in this scenario (Westbrook et al., 2018; Thomas et al., 2017).

Once the medical officer completed Peter's discharge medication documentation, the nurse in charge of Peter's ward sent it to the hospital pharmacist, along with 40 other paper based discharge medication charts. Integration of a pharmacist review in discharge medication management is common practice and has proven to be effective in reducing errors (Bishop et al., 2015).

The pharmacist was also not accustomed to using paper based documentation and was unfamiliar with the discharge medication form itself. The pharmacist was the only pharmacist on duty due to staff illness and so experienced heightened stress due to the increased workload and increased pressure from ward staff requesting discharge medication. Research has confirmed the detrimental impact that work related stress, work process inefficiencies (such as having to move from an electronic medication management system to a paper based system), high workloads and moral distress has on pharmacy staff and the increased incidence of medication errors (Williams, 2007). Due to his increased workload and stress, the pharmacist tried to reduce his workload and assumed that Peter's discharge medication form would be checked by Peter's General Practitioner (GP) on his arrival back at the facility. As a result, he did not dispense Peter's medication but ticked off his discharge medication form as being correct and sent it back to the ward to accompany Peter to the aged care facility.

Interdisciplinary communication and collaboration has been identified as one of the major causes of medication errors and poor patient care (Siegele, 2009). In this case ineffective written and verbal communication in relation to Peter's prescriptions contributed to the medication error (Kazaoka et al., 2007). Poor communication between the aged care facility nurse and the GP compounded this medication error. Nurse Amy did fax the discharge medication documentation to the GP's office but he would not receive the fax until the next working day which was Monday. The facility's policy was for nursing staff who received documentation related to a change in a resident's medications or condition to ring the resident's GP immediately and inform them of the 
details of the change. If they were unable to contact the GP they were to leave a message and try again later until they had contacted the GP.

Decreased staff knowledge, skills or expertise has been found to contribute significantly to medication errors (Folkmann and Rankin, 2010; Ulanimo et al., 2007). Amy had not been orientated fully to her role as she had commenced employment with the organisation on Friday and was put in charge of the facility on her Saturday shift. It can be assumed that if Amy had completed her employee orientation and as a result had increased knowledge regarding the facility's usual processes, she might have telephoned Peters' GP and informed him of the medication changes on Saturday and so detected the error in Peter's discharge medication documentation.

Once Nurse Amy received the discharge documentation, she read through it then filed it. She did fax the discharge medication order to the after-hours pharmacy servicing the aged care facility but did not recognise that the order contained both oral hyploglycaemics and insulin. She placed the order in Peter's medication folder and moved on to administer medications for the next resident. The pharmacist who received the faxed discharge medication order the next day was a locum pharmacist who did not know Peter and assumed the hospital generated medication order was correct. He filled the prescription for both oral hypoglycaemics and Lantus and organised for the medication to be delivered to the facility on Sunday morning.

Amy was a new graduate nurse in her first role as a registered Nurse. She had not fully completed her organisational orientation and had commenced working in the facility on the Friday. When she came on duty on Saturday afternoon she was placed in charge of the facility due to staff illness. This meant that she was the sole registered Nurse on duty for that shift with only patient care staff members rostered on with her. She discussed her concerns regarding her inexperience with the registered Nurse on the morning shift but was told that she "would be fine". Workplace support and supportive relationships with other staff members are vital for the assimilation of graduate nurses into the workplace (Sahay et al., 2015). Unsupportive and isolating behaviours such as Amy experienced will likely increase staff stress and the incidence of poor care including medication errors.

Graduate nurses have been shown to possess insufficient medication knowledge when commencing their first position as a registered Nurse, which may be the result of inadequate nursing education or reduced levels of student nurse engagement during their training (Simonsen et al., 2014). As a new graduate, Amy had limited experience in medication administration and very little knowledge regarding diabetic medications. She had administered medication in a simulated environment at University and under direct supervision on clinical placement, but had not administered medications to a diabetic patient before. Simulation education in medication administration is a highly effective method of teaching student nurses how to safely administer medications in a variety of situations but it is limited by its very nature (Zimmerman and House, 2016).

Amy was also reluctant to contact the facility's Director of Nursing to discuss her inexperience and request assistance as she had just started work at the facility and did not want to make an unfavourable impression as a new employee. As Amy was the only registered Nurse on shift, she also received multiple calls from the other staff throughout the shift requesting her assistance with residents who had fallen or required pain assessment and analgesia.

Due to Amy's heightened anxiety as a result of these frequent calls and her lack of clinical experience, she assumed that the hospital generated discharge medication order was correct and so administered the oral hypoglycaemics as ordered. Another factor in the medication error process was that Amy did not know Peter and his history so was not familiar with his usual medications.

Three potential breaches in the administration of medication in aged care facilities include complex medication charts with unclear ordering and administration records, poor local practices of medication administration and poor communication between providers and the administration of medications (Tariq et al. , 2013). Other factors include limited point of care information access, multiple information storage, inadequate staff communication, high workload and management expectations (Tariq et al., 2015). 
Factors were investigated and confirmed by reviewing documentation and consultation with those engaged in the medication error incident. The root cause analysis identified factors impacting on the medication error as follows:

1. Errors made by the medical officer in the transcription stage from the inpatient medication chart to the patient discharge medication chart. These factors included handwritten prescriptions and documentation not electronic medication ordering and lack of concentration during the medication transcription process due to high workload, stress and frequent interruptions.

2. Failure of the pharmacist to detect the error on receipt of the discharge medication form due to higher than normal workloads, an unfamiliar paper based documentation system and decreased pharmacy staff on duty leading to increased stress and frequent interruptions.

3. Poor communication between the aged care facility staff and Peters' GP on his arrival to the facility. The nurse read the discharge form but did not contact the GP by phone but sent a fax to his office which he would not receive until the next working day.

4. The pharmacy which supplied medication for the aged care facility was staffed by a locum pharmacist who filled the order for Lantus without questioning the order as he did not know Peter and thought the hospital order was valid.

5. The nurse was a recent graduate registered Nurse and had limited work and life experience. She did not know the residents in the facility, and experienced significant stress and a high workload due to being the only registered Nurse rostered on for the shift and the frequent interruptions by other staff numbers. Due to her clinical inexperience and increased stress, she did not check Peter's medications, especially their use and dosage prior to administration, assuming that the medication order generated from the hospital was correct.

\section{Analysis process}

\section{What is best practice for reducing medication errors?}

The factors that contribute to medication errors are complex and multifaceted, and can be divided into two sub-groups: those caused by systems errors and those caused by individual health care professional issues (McBride-Henry and Foureur 2006). When considering the factors relating to this medication error, the medication management system, communication and organisational culture were significant and problematic.

The use of computerised physician ordering systems including bar-code verification technology to confirm the right person, drug, dose, route and time prior to administration in hospital and aged care facilities has been shown to reduce medication errors at the initial stage (Bates and Gawande, 2003; Koppel et al., 2008; Poon et al., 2006 ). Computerised systems have been shown to prevent inadvertent omission of therapy, the prescription of a previously ceased medicine, prescription of the wrong drug, dose or frequency and duplication of therapy after discharge (Vira et al., 2006; Gleason et al., 2010). As discussed in this scenario, the usual hospital medication management system was computerised and the move to paper based documentation when it was inaccessible was a significant factor in the initiation of this medication error, increasing the likelihood of error.

Staff performance obstacles including fatigue, decreased cognition, poor communication and decision making, have also been reported to impact on safe medication management (Carayon et al., 2005). A number of clinicians in this scenario experienced increased stress and anxiety due to poor communication, increased workloads, time constraints and the use of unfamiliar documentation which have impacted on Peter's medication management.

The implementation of interventions such as vests worn by nurses administering medications to alert others that they were not to be disturbed and requesting other staff to attend to telephone calls and requests, have been effective in minimising interruptions during medication administration (Raban and Westbrook, 2013; Westbrook et al., 2010). It is unlikely that 
wearing a vest during medication administration would have been effective in this scenario as Amy was the only registered Nurse rostered on for the shift and so was responsible for medication administration and attending to all residents needing assistance or analgesia.

\section{Findings}

This article explored the impact of a variety of factors in a medication error for a patient who transitioned from hospital to an aged care facility. The identified factors include:

- lack of staff training on the use of paper based documentation;

- inadequate knowledge and experience related to the administration of medications;

- high workloads, poor communication, distractions and disruptions lead to fatigued, stressed health care providers and poor communication between health professionals; and

- medication errors are one of the leading causes of poor patient care and adverse patient outcomes, so increased understanding regarding the factors related to medication errors is crucial in the reduction of medication errors (Caravon et al., 2014).

Medication errors are a multidisciplinary issue and require a multidisciplinary management approach including staff training and support (Okuyama et al., 2014). A systems approach to medication error management where near misses and system problems are identified in addition to actual medication errors may also be very effective in medication error reduction (Carayon et al., 2014). Decreased knowledge regarding medications and their actions is a persistent problem with medical staff and nurses often exhibiting inadequate knowledge of dosage and action which can increase the incidence of medication errors (Chang et al., 2015). Increased workloads and decreased staffing levels have also been shown to negatively impact on safe medication management and need to be recognised as a significant factor in medication errors (Carayon et al., 2014).

\section{Conclusion}

Research indicates that medication errors in aged care facilities are prevalent with 40 per cent of aged care residents regularly receiving at least one potentially inappropriate medication (Hamilton et al., 2009). High-risk situations, polypharmacy and transitions of care have been identified as three key areas to be addressed by health care organisations to protect patients from adverse medication events and subsequent harm (WHO, 2017). Resident age, number of medications, multi co- morbidity and staff competence are other factors impacting on safe medication administration (Panagioti et al. , 2015; Damen et al. , 2017; Ryan et al., 2014).

The case study presented in this paper highlights the risk factors and events that contributed to the identified medication error and is important in the discussion regarding medication errors for elderly individuals transitioning from hospital to aged care facilities. A variety of incidents occurred from prescription to administration of medication for Peter resulting in a significant medication error. Human error based in fatigue, high stress and workloads are common and can start the progression of a medication error such as this. If not detected, the error can quickly compound and progress at an alarming rate until the medication error occurs (Savvato and Efstratios, 2014). There is no one person to blame in regard of this medication error but the sequence of events set the process in motion, resulting in the medication error.

A recent review of medication management practice and policies identified that poor transfer of information, inadequate arrangements for continuing medicines supply, the absence of an up-to-date medication chart, missed or significantly delayed doses, problems accessing medication information and, supply of suitably packed medicines on short notice can increase the incidence of medication errors (McBane et al., 2015).

Further research is needed to explore the factors leading to medication errors and strategies which can be used to minimise medication errors into the future. 


\section{References}

Barker, K.N., Flynn, E.A., Pepper, G.A., Bates, D.W. and Mikeal, R.L. (2002), "Medication errors observed in 36 health care facilities", Archives of Internal Medicine, No. 162, pp. 1897-903.

Bates, D.W. and Gawande, A.A. (2003), "Improving safety with information technology”, New England Journal of Medicine, Vol. 348 No. 25, pp. 2526-534.

Bishop, M.A., Cohen, B.A., Billings, L.K. and Thomas, E.V. (2015), "Reducing errors through discharge medication reconciliation by pharmacy services", American Journal of Health-System Pharmacy, Vol. 72 No. 17 S2, pp. S120-6.

Britt, H.C., Harrison, C.M. and Miller, G.C. (2008), "Prevalence and patterns of multimorbidity in Australia", Medical Journal of Australia, Vol. 189, pp. 72-7.

Carayon, P., Gurses, A.P., Hundt, A.S. et al. (2005), "Performance obstacles and facilitators of healthcare providers", in Korunka, C. and Hoffmann, P. (Eds), Change and Quality in Human Service Work, Hampp Publishers, Munchen, pp. 257-76.

Carayon, P., Wetterneck, T.B., Rivera-Rodriguez, A.J., Hundt, A.S., Hoonakker, P., Holden, R. and Gurses, A.P. (2014), "Human factors systems approach to healthcare quality and patient safety", Applied Ergonomics, Vol. 45 No. 1, pp. 14-25.

Damen, N.L., Baines, R., Wagner, C. and Langelaan, M. (2017), "Medication-related adverse events during hospitalization: a retrospective patient record review study in The Netherlands", Pharmacoepidemiology and Drug Safety, Vol. 26 No. 1, pp. 32-9.

Department of Health and Ageing (2012), Guiding Principles for Medication Management in Residential Aged Care, Commonwealth of Australia, Canberra.

Dolanski, M.A., Dreushel, K., Helba, M. and Courtney, K. (2013), "Nursing student medication errors: a case study using root cause analysis", Journal of Professional Nursing, Vol. 29 No. 2, pp. 102-08.

Dwyer, R., Gabbe, B., Stoelwinder, J.U. and Lowthian, J. (2014), "A systematic review of outcomes following emergency transfer to hospital for residents of aged care facilities", Age and Ageing, Vol. 43 No. 6, pp. 759-66.

Elliott., R.A., Tran., T., Taylor., S.E., Harvey., P.A., Belfrage, M.,.K., Jennings, R.J. et al. (2012), "Gaps in continuity of medication management during the transition from hospital to residential care: an observational study (MedGap Study)", Australasian Journal on Ageing, Vol. 31 No. 4, pp. 247-54.

Fialova, D. and Onder, G. (2009), "Medication errors in elderly people: contributing factors and future perspectives", British Journal of Clinical Pharmacology, Vol. 67 No. 6, pp. 641-5.

Folkmann, L. and Rankin, J. (2010), "Nurses' medication work: what do nurses know?", Journal of Clinical Nursing, Vol. 19 Nos 21-22, pp. 3218-26.

Gautam, P.L. (2013), "Minimizing medication errors: moving attention from individual to system", Journal of Anaesthesia, Vol. 29, pp. 293-4.

Gleason, K.M., McDaniel, M.R., Feinglass, J., Baker, D.W., Lindquist, L., Lissm, D. et al. (2010), "Results of the medications at transitions and clinical handoffs (MATCH) study: an analysis of medication reconciliation errors and risk factors at hospital admission", Journal of General Intern Medicine, Vol. 25, pp. 441-7.

Gurwitz, J.H., Field, T.S., Avorn, J., McCormick, D., Jain, S., Eckler, M. and Bates, D.W. (2000), "Incidence and preventability of adverse drug events in nursing homes", The American Journal of Medicine, Vol. 109 No. 2, pp. 87-94.

Hamilton, H.J., Gallagher, P.F. and O’Mahony, D. (2009), “Inappropriate prescribing and adverse drug events in older people", BMC Geriatrics, Vol. 9 No. 1, p. 5.

James, J.T. (2013), "A new, evidence-based estimate of patient harms associated with hospital care”, Journal of Patient Safety, Vol. 9 No. 3, pp. 122-8.

Kazaoka, T., Ohtsuka, K., Ueno, K. and Mori, M. (2007), "Why nurses make medication errors: a simulation study", Nurse Education Today, Vol. 27 No. 4, pp. 312-7.

Koppel, R., Leonard, C.E., Localio, A.R., Cohen, A., Auten, R. and Strom, B.L. (2008), "Identifying and quantifying medication errors: evaluation of rapidly discontinued medication orders submitted to a computerized physician order entry system", Journal of the American Medical Informatics Association, Vol. 15 No. 4, pp. 461-5. 
Leach, H. (2006), "National inpatient medication chart implementation", Journal of Pharmacy Practice and Research, Vol. 36 No. 1, pp. 6-7.

McBane, S.E., Dopp, A.L., Abe, A., Benavides, S., Chester, E.A., Dixon, D.L. and Schwartz, A.H. (2015), "Collaborative drug therapy management and comprehensive medication management", Pharmacotherapy: The Journal of Human Pharmacology and Drug Therapy, Vol. 35 No. 4.

McBride-Henry, K. and Foureur, M. (2006), "Medication administration errors: understanding the issues", Australian Journal of Advanced Nursing, Vol. 23 No. 3, pp. 33-41.

Nuckols, T.K., Smith-Spangler, C., Morton, S.C., Asch, S.M., Patel, V.M., Anderson, L.J. and Shekelle, P.G. (2014), "The effectiveness of computerized order entry at reducing preventable adverse drug events and medication errors in hospital settings: a systematic review and meta-analysis", Systematic Reviews, Vol. 3 No. 1, p. 56.

Okuyama, A., Wagner, C. and Bijnen, B. (2014), "Speaking up for patient safety by hospital-based health care professionals: a literature review", BMC Health Services Research, Vol. 14 No. 1, p. 61.

Panagioti, M., Stokes, J., Esmail, A., Coventry, P., Cheraghi-Sohi, S., Alam, R. and Bower, P. (2015), "Multimorbidity and patient safety incidents in primary care: a systematic review and meta-analysis", PLoS One, Vol. 10 No. 8, e0135947.

Panosh, N., Drew, R. and Sharpe, M. (2012), "Effect of closed-loop order processing on the time to initial antimicrobial therapy", American Journal of Health-System Pharmacy, Vol. 69, pp. 1423-26.

Pierce, D. and Fraser, G. (2009), "An investigation of medication information transfer and application in aged care facilities in an Australian rural setting", Rural and Remote Health, No. 3, p. 1090.

Poon, E.G., Cina, J.L., Churchill, W., Patel, N., Featherstone, E., Rothschild, J.M. and Gandhi, T.K. (2006), "Medication dispensing errors and potential adverse drug events before and after implementing bar code technology in the pharmacy", Annals of Internal Medicine, Vol. 145 No. 6, pp. 426-34.

Raban, M.Z. and Westbrook, J.I. (2013), "Are interventions to reduce interruptions and errors during medication administration effective? A systematic review”, British Medical Journal, Vol. 23 No. 5, pp. 414-21.

Ryan, C., Ross, S., Davey, P., Duncan, E.M., Francis, J.J., Fielding, S. and Maxwell, S. (2014), "Prevalence and causes of prescribing errors: the PRescribing outcomes for trainee doctors engaged in clinical training (PROTECT) study", PLoS One, Vol. 9 No. 1, p. e79802.

Sahay, A., Hutchinson, M. and East, L. (2015), "Exploring the influence of workplace supports and relationships on safe medication practice: a pilot study of Australian graduate nurses", Nurse Education Today, Vol. 35 No. 5, pp. e21-6.

Sammer, C.E., Lykens, K., Singh, K.P., Mains, D.A. and Lackan, N.A. (2010), "What is patient safety culture? A review of the literature", Journal of Nursing Scholarship, Vol. 42 No. 2, pp. 156-65.

Savvato, K. and Efstratios (2014), "An inside look into the factors contributing to medication errors in the clinical nursing practice", Health Science Journal, Vol. 8 No. 1, pp. 32-44.

Shehab, N., Lovegrove, M.C., Geller, A.I., Rose, K.O., Weidle, N.J. and Budnitz, D.S. (2016), "US emergency department visits for outpatient adverse drug events, 2013-2014", Jama, Vol. 316 No. 20, pp. 2115-25.

Siegele, P. (2009), "Enhancing outcomes in a surgical intensive care unit by implementing daily goals tools", Critical Care Nurse, Vol. 29 No. 6, pp. 58-69.

Simonsen, B.O., Daehlin, G.K., Johansson, I. and Farup, P.G. (2014), "Differences in medication knowledge and risk of errors between graduating nursing students and working registered nurses: comparative study", BMC Health Services Research, Vol. 14 No. 1, p. 580.

Tariq, A., Georgiou, A. and Raban, M. (2015), "Underlying risk factors for prescribing errors in long term aged care: a qualitative study", British Medical Journal, doi: 10.1136/bmjqs-2015-004589.

Tariq, A., Georgiou, A. and Westbrook, J. (2013), "Medication errors in residential aged care facilities: a distributed cognition analysis of the information exchange process", International Journal of Medical Informatics, Vol. 82 No. 5, pp. 299-312.

Thomas, L., Donohue-Porter, P. and Fishbein, J.S. (2017), "Impact of interruptions, distractions, and cognitive load on procedure failures and medication administration errors", Journal of Nursing Care Quality, Vol. 32 No. 4, pp. 309-17. 
Ulanimo, V.M., O Leary, K. and Conolly, C. (2007), "Nurses' perceptions of causes of medication errors and barriers to reporting”, Journal of Nursing Care Quaityl, Vol. 22, pp. 28-33.

Vira, T., Colquhoun, M. and Etchells, E.E. (2006), "Reconcilable differences: correcting medication errors at hospital admission and discharge", Quality and Safety in Health Care, Vol. 15, pp. 122-6.

Westbrook, J., Woods, A., Dunsmuir, M. and Day, R. (2010), "Association of interruptions with an increased risk and severity of medication administration errors", Archives of Internal Medicine, Vol. 170 No. 8.

Westbrook, J.I., Raban, M., Walter, S.R. and Douglas, H. (2018), "Task errors by emergency physicians are associated with interruptions, multitasking, fatigue and working memory capacity: a prospective, direct observation study", BMJ Quality and Safety.

Williams, D.J.P. (2007), “Medication errors”, Royal College of Physicians of Edinburgh, Vol. 37 No. 4, p. 343.

World Health Organisation (2017), World Health Statistics 2017: Monitoring Health for the SGD's, World Health Organisation.

Zimmerman, D.M. and House, P. (2016), "Medication safety: simulation education for new RNS promises an excellent return on investment", Nursing Economics, Vol. 34 No. 1, p. 49.

\section{Further reading}

Avery, A.J., Rodgers, S., Cantrill, J.A., Armstrong, S., Cresswell, K., Eden, M. and Prescott, R.J. (2012), "A pharmacist-led information technology intervention for medication errors (PINCER): a multicentre, cluster randomised, controlled trial and cost-effectiveness analysis", The Lancet, Vol. 379 No. 9823, pp. 1310-9.

Suzman, R., Beard, J.R., Boerma, T. and Chatterji, S. (2015), "Health in an ageing world-what do we know?", The Lancet, Vol. 385 No. 9967, pp. 484-6.

\section{Corresponding author}

Julia Gilbert can be contacted at: julia.gilbert@federation.edu.au

For instructions on how to order reprints of this article, please visit our website:

www.emeraldgrouppublishing.com/licensing/reprints.htm

Or contact us for further details: permissions@emeraldinsight.com 